\title{
Diet behavior of Employees at a Medical Sciences University in Tehran, Iran: Iran Health Day 2015
}

\author{
Mohsen Saberi Isfeedvajani ${ }^{1}$, Ali Akbar Karimi Zarchi² ${ }^{*}$, Ali Mehrabi Tavana ${ }^{3}$ \\ ${ }^{1}$ Medicine, Quran and Hadith Research Center \& Department of Community Medicine, Faculty of Medicine, Baqiyatallah \\ University of Medical Sciences, Tehran, Iran \\ ${ }^{2}$ Department of Epidemiology and Biostatistics \& Department of Community Medicine, Faculty of Health \& Faculty of Medicine, \\ Baqiyatallah University of Medical Sciences, Tehran, Iran \\ ${ }^{3}$ Health Management Research Center and Department of Community Medicine, Faculty of Medicine, Baqiyatallah University of \\ Medical Sciences, Tehran, Iran
}

Corresponding Author: Ali Akbar Karimi Zarchi, Associate Professor, Department of Community Medicine, 8C Floor, Baqiyatallah Hospital, Molla Sadra Ave, Tehran, Iran. Tel: +982181243850, Fax: +982188037561, Email: alikarimi_in@yahoo.com

Received March 29, 2016; Accepted May 14, 2016; Online Published September 25, 2016

\begin{abstract}
Introduction: Diet behavior plays an important role in non-communicable disease (NCD). The theme of World Health Day 2015 was "improve food safety from farm to plate (always and everywhere)." The present study assessed the diets of employees at a medical university in Tehran, Iran on Iran Health Day 2015.

Methods: This cross-sectional study assessed the diets of 468 employees of a medical university in Tehran on World Health Day 2015. The subjects completed questionnaires on demographics and diet behavior. The data was analyzed using SPSS version 22 software. Independent samples $t$ test or its non-parametric equivalent were used to compare groups.

Results: The mean age of the subjects was 33.45 (SD: 13.19) years. Of these $52.7 \%$ were male, $50.8 \%$ had university degrees and $42 \%$ were obese or overweight. The mean score of the diet questionnaire was $26.15( \pm 4.46)$. The highest score was 36 and the lowest was 15 . Although the diet questionnaire score was significantly higher for female subjects, there was no significant relationship between educational level and diet questionnaire score.

Conclusion: This study showed that few employees ate breakfast and more than $50 \%$ did not restrict their use of sugar and sweets. Female employees scored higher on the diet questionnaire. Overall, diet should be improved through attractive types of continuous education.
\end{abstract}

Keywords: Diet, Behavior, Lifestyle, Iran, Global health

Citation: Saberi Isfeedvajani M, Karimi Zarchi AA, Mehrabi Tavana A. Diet behavior of employees at a medical sciences university in Tehran, Iran: Iran Health Day 2015. Int J Travel Med Glob Health. 2016;4(3):92-95. doi:10.20286/ijtmgh-040305.

\section{Introduction}

Worldwide, the burden of communicable disease and maternal, neonatal, and nutritional disorders declined between 1990 and 2013, whereas the burden of non-communicable disease (NCD) increased. ${ }^{1,2}$ A sustainable development goal is a global framework to reduce premature deaths from NCDs by one-third. Nutrition-related NCD is important because remarkable transformations of food systems have resulted in a rapid increase on NCDs in low- and middle-income countries. $^{3}$

Diet plays an important role in NCDs such as cardiovascular disease, ${ }^{2,4-13}$ diabetes, ${ }^{2,5,8,12}$ cancer, ${ }^{2,12,14}$ mental disorders, ${ }^{15-17}$ and chronic obstructive pulmonary disease. ${ }^{18}$ Unhealthy diet is a increases the risk of NCDs and provide an opportunity to intervene perfect, appropriately, and synergistically on more than one risk behavior concurrently to prevent NCDs as a whole. ${ }^{12}$ It has been recommended that the workplace is an appropriate filed to evaluate lifestyle intervention such as promotion of a healthy diet because many adults, regardless of socio-economic status, lifestyle, and risk profile can be targeted at once. ${ }^{9}$

Globalization of the food supply has increased the need to strengthen food safety. For this reason, the World Health Organization (WHO) is promoting efforts to improve food safety by making the theme of World Health Day 2015 "improve food safety from farm to plate (always and everywhere)." 19 The first step to promoting a healthy diet in a given society is to assess diet behavior; thus, the present study assessed the diet behavior of employees at a medical sciences university in Tehran on Health Day 2015. 


\section{Methods}

This cross-sectional study was carried out from April 21, 2015 to April 27, 2015 (Iranian Health Week) at a medical university in Tehran. The De Morgan table was used to calculate the sufficient number of cases as 364 and nonprobability sampling used. The subjects were employees of the university who completed demographic and diet behavior questionnaires. Demographic questionnaire consisted of variables such as age, gender, educational level, weight and height.

The diet behavior questionnaire included questions about the consumption of sugar and sweets, bread, cereals, and similar foods, fruits, vegetables, dairy products, proteins such as meat, fish, chicken, eggs and nuts and whether or not the subject read food product labels and ate breakfast. This questionnaire was the Persian version of the health-promoting lifestyle profile (HPLP) validated by Zeidi et al. ${ }^{20}$ The questionnaire contained nine questions, with possible responses of 1 (never), 2 (sometimes), 3 (often) and 4 (routinely). The highest score on the diet behavior questionnaire was 36 and the lowest was 9. A higher score indicates better diet behavior.

\section{Statistical Analysis}

The data was analyzed using SPSS version 22. $P$ value lower than .05 was considered significant for all analyses. Normal distribution was tested by one-sample Kolmogorov-Smirnov test. The independent samples $t$ test and its non-parametric equivalent were used to compare age, body mass index (BMI) and diet behavior score by gender and educational level.

\section{Results}

Of the 468 participants, $52.7 \%$ were male, $50.8 \%$ had university degrees and $42 \%$ were obese or overweight. The mean age $( \pm$ SD) of subject was $33.45( \pm 13.19)$. The mean $( \pm$ SD) diet behavior questionnaire score was $26.15( \pm 4.46)$. Tables 1 and 2 show the descriptive data.

The diet behavior questionnaire scores and age were significantly higher in female subjects whereas the BMI was

Table 1. Demographics and Diet Behavior Score of Participants

\begin{tabular}{lc}
\hline & Mean \pm SD \\
\hline Age $(\mathrm{y})$ & $33.45 \pm 13.19$ \\
BMI $\left(\mathrm{kg} / \mathrm{m}^{2}\right)$ & $24.20 \pm 3.44$ \\
Diet behavior score & $26.15 \pm 4.46$ \\
\hline
\end{tabular}

Table 2. Gender, Educational Level and Weight of Participants

\begin{tabular}{lcc}
\hline & No. & Validity (\%) \\
\hline Gender & & \\
Male & 235 & 52.7 \\
Female & 211 & 47.3 \\
Education level & \\
$\quad$ University degree & 233 & 50.8 \\
High school diploma or less & 226 & 49.2 \\
Weight & & \\
Obese or overweight & 178 & 42 \\
$\quad$ Normal & 246 & 58 \\
\hline
\end{tabular}

significantly higher in males (Table 3).

Although there was no significant relationship between education level and diet behavior questionnaire score, age and BMI were found to be significantly higher in employees who had a high school diploma or fewer years of education (Table 4).

\section{Discussion}

The results showed that only $58 \%$ of participants had a normal BMI and that the diet behavior scores were higher for females. There was no significant relationship between diet behavior score and education level.

Kim et $\mathrm{a}^{21}$ reported that education and gender are significant determinants of health-promoting lifestyles among Arabs and Koreans in the United Arab Emirates. Fincham et $\mathrm{al}^{22}$ showed that demographic variables such as gender could explain a health-promoting lifestyle. Shaheen et al studied healthpromoting behavior at a university in Jordan. The mean $( \pm$ SD) score of HPLP nutrition subscale of students was 20.66 $( \pm 4.37)$ which was lower than for the subjects of the present study. They also found that gender could be a determinant of a health-promoting lifestyle. ${ }^{23}$

Mohammadian and Mousavi studied the lifestyles of university students in Kashan, Iran and found a significant relationship between gender and the nutritional status of subjects. ${ }^{24}$ Geok et $\mathrm{al}^{25}$ asked student nurses in Malaysia to complete the HPLP and found that the spiritual growth, interpersonal relations and stress management had highest score respectively while the physical activity, health responsibility and nutrition had lowest score respectively.

Hwang et $\mathrm{al}^{26}$ studied predictors of health behavior in Korean blue-collar workers and showed that education level was a significant predictor. Shafieyan et al studied the lifestyle of patients referred to health care centers in Ilam, Iran in 2014. They reported the mean $( \pm S D)$ of the HPLP nutrition scale to be $26.35( \pm 3.47)$ for hypertensive patients and $26.65( \pm 3.74)$

Table 3. Comparison of Age, BMI and Diet Behavior Score by Gender

\begin{tabular}{lccc}
\hline & Gender & Mean \pm SD & P Value \\
\hline \multirow{2}{*}{ Age } & Male & $30.97 \pm 11.15$ & \multirow{2}{*}{ Female } \\
\multirow{2}{*}{ BMI } & $36.16 \pm 14.79$ & \\
& Male & $24.65 \pm 2.90$ & \multirow{2}{*}{.007} \\
\multirow{2}{*}{ Diet behavior score } & Female & $23.69 \pm 4.00$ & \\
& Male & $25.22 \pm 4.24$ & \multirow{2}{*}{0001} \\
\hline
\end{tabular}

Abbreviation: BMI, body mass index.

Table 4. Comparison of Age, BMI and Diet Behavior Score by Educational Level

\begin{tabular}{llll}
\hline & Educational Level & Mean \pm SD & P Value \\
\hline \multirow{2}{*}{ Age } & High school diploma or less & $35.45 \pm 15.30$ & \multirow{2}{*}{.002} \\
& University degree & $31.56 \pm 10.48$ & \\
\multirow{2}{*}{ BMI } & High school diploma or less & $24.83 \pm 3.38$ & \multirow{2}{*}{$<.0001$} \\
Diet & University degree & $23.60 \pm 3.41$ & \\
$\begin{array}{l}\text { behavior } \\
\text { score }\end{array}$ & High school diploma or less & $26.12 \pm 4.47$ & \multirow{2}{*}{ University degree } \\
\hline
\end{tabular}

Abbreviation: BMI, body mass index. 
for the control group. There was no significant difference between the hypertensive and control groups. ${ }^{27}$ This result is compatible with the findings of the present study.

Mahdipour et al studied the effect of educational intervention on a health-promoting lifestyle and reported that although nutrition was one dimension of lifestyle, its score did not change significantly after educational intervention. ${ }^{28}$ Safabakhsh et $\mathrm{al}^{29}$ examined the effect of health-promoting programs on patient lifestyle after coronary artery bypass surgery and found that the HPLP nutrition subscale score increased significantly after intervention in the experimental group $(19.7 \pm 0.135$ versus $31.3 \pm 0.258)$. The HPLP nutrition subscale score of these patients before intervention was lower than that of the present study, although the score was higher after intervention.

Chen et al found an association between breakfast eating habits and health-promoting lifestyle on suboptimal health status in Southern China and showed that $90 \%$ of samples had a normal BMI and $19.6 \%$ of participants reported "scarce" breakfast eating habits. They found a significant association between breakfast eating habits and healthy lifestyle. ${ }^{30}$ In the present study, $57.7 \%$ of personnel always ate breakfast and $58 \%$ had a normal BMI. Inal et $\mathrm{al}^{31}$ found that only $26.6 \%$ of subjects ate breakfast as a family and $57.8 \%$ ate breakfast at home. They reported that $68 \%$ of mothers had a normal BMI. These results are somewhat compatible with the results of the present study.

\section{Conclusion}

The present study showed that, although diet is an important factor in NCDs, diet behavior was not compatible with a healthy diet. The results indicate that females paid more attention to a healthy diet. Eating breakfast daily is important and other healthy diet behaviors must be encouraged.

\section{Authors Contributions}

All authors contributed equally to the preparation of this paper.

\section{Conflict of Interest Disclosures \\ No conflict of interest.}

\section{Ethical Approval \\ Not applicable.}

\section{Funding/Support}

Self-funded research.

\section{Acknowledgments}

The authors would like to thank the Clinical Research Development Unit of Baqiyatallah Hospital for their kind cooperation.

\section{References}

1. Murray CJ, Barber RM, Foreman KJ, et al. Global, regional, and national disability-adjusted life years (DALYs) for 306 diseases and injuries and healthy life expectancy (HALE) for 188 countries, 1990-2013: quantifying the epidemiological transition. Lancet. 2015;386(10009):2145-2191.

2. Isfeedvajani MS, Zarchi AAK, Heris AM, Sajjadi F, Tavana AM. Evaluation of personnel blood pressure and its risk factors in
Research Highlights

\section{What Is Already Known?}

Diet behavior plays an important role in NCD. Healthy diet could prevent risks of many NCDs.

\section{What This Study Adds?}

Although diet is an important factor in NCDs, diet behavior was not compatible with a healthy diet. Women pay more attention to a healthy diet. Eating breakfast daily is important and other healthy diet behaviors must be encouraged.

university affiliated medical centers: Iran's Health Day 2013. Med J Islam Repub Iran. 2014;28:36.

3. Hawkes C, Popkin BM. Can the sustainable development goals reduce the burden of nutrition-related non-communicable diseases without truly addressing major food system reforms? BMC Med. 2015;13:143. doi:10.1186/s12916-015-0383-7.

4. Åkesson A, Larsson SC, Discacciati A, Wolk A. Low-risk diet and lifestyle habits in the primary prevention of myocardial infarction in men: a population-based prospective cohort study. J Am Coll Cardiol. 2014;64(13):1299-1306. doi:10.1016/j. jacc.2014.06.1190.

5. Long GH, Cooper AJ, Wareham NJ, Griffin SJ, Simmons RK. Healthy behavior change and cardiovascular outcomes in newly diagnosed type 2 diabetic patients: a cohort analysis of the ADDITION-Cambridge study. Diabetes Care. 2014;37(6):17121720. doi:10.2337/dc13-1731.

6. Spring B, Moller AC, Colangelo LA, et al. Healthy lifestyle change and subclinical atherosclerosis in young adults: Coronary Artery Risk Development in Young Adults (CARDIA) study. Circulation. 2014;130(1):10-17. doi:10.1161/circulationaha.113.005445.

7. Young DR, Reynolds K, Sidell M, et al. Effects of physical activity and sedentary time on the risk of heart failure. Circ Heart Fail. 2014;7(1):21-27. doi:10.1161/circheartfailure.113.000529.

8. Lamichhane AP, Liese AD, Urbina EM, et al. Associations of dietary intake patterns identified using reduced rank regression with markers of arterial stiffness among youth with type 1 diabetes. Eur J Clin Nutr. 2014;68(12):1327-1333. doi:10.1038/ejcn.2014.96.

9. Groeneveld IF, Proper KI, van der Beek AJ, Hildebrandt VH, van Mechelen W. Short and long term effects of a lifestyle intervention for construction workers at risk for cardiovascular disease: a randomized controlled trial. BMC Public Health. 2011;11:836.

10. Huffman KM, Sun JL, Thomas L, et al. Impact of baseline physical activity and diet behavior on metabolic syndrome in a pharmaceutical trial: results from NAVIGATOR. Metabolism. 2014;63 (4):554-561. doi:10.1016/j.metabol.2014.01.002.

11. Huffman MD, Capewell S, Ning H, Shay CM, Ford ES, Lloyd-Jones DM. Cardiovascular health behavior and health factor changes (1988-2008) and projections to 2020 results from the national health and nutrition examination surveys. Circulation. 2012;125(21):2595-2602. doi:10.1161/ circulationaha.111.070722.

12. Spring B, Schneider K, McFadden HG, et al. Multiple behavior changes in diet and activity: a randomized controlled trial using mobile technology. Arch Intern Med. 2012;172(10):789-796. doi:10.1001/archinternmed.2012.1044.

13. Schweier R, Romppel M, Richter C, et al. A web-based peermodeling intervention aimed at lifestyle changes in patients with coronary heart disease and chronic back pain: sequential controlled trial. J Med Internet Res. 2014;16(7):e177. doi:10.1001/ archinternmed.2012.1044.

14. Focht BC, Lucas AR, Grainger E, Simpson C, Thomas-Ahner JM, Clinton SK. The Individualized Diet and Exercise Adherence Pilot Trial (IDEA-P) in prostate cancer patients undergoing androgen deprivation therapy: study protocol for a randomized controlled trial. Trials. 2014;15:354. doi:10.1186/1745-6215-15-354.

15. Roohafza H, Ali Kabir MD M, Sadeghi M, Shokouh P, AalaeiAndabili SH, Sarrafzadegan N. Effect of psychological distress 
on weight concern and weight control behaviors. Arch Iran Med. 2014;17(9):608.

16. Konikowska K, Regulska-llow B, Rozanska D. The influence of components of diet on the symptoms of ADHD in children. Rocz Panstw Zakl Hig. 2012;63(2):127-134.

17. Norton MC, Dew J, Smith H, et al. Lifestyle behavior pattern is associated with different levels of risk for incident dementia and Alzheimer's disease: the Cache County study. J Am Geriatr Soc. 2012;60(3):405-412. doi:10.1111/j.1532-5415.2011.03860.x.

18. Hanson C, Rutten EP, Wouters E, Rennard S. Influence of diet and obesity on COPD development and outcomes. Int J Chron Obstruct Pulmon Dis. 2014;9:723-733. doi:10.2147/copd.s50111.

19. Mahapatra S, Chaly PE, Girija AS. Effectiveness of various disinfection techniques on vegetables and fruits: an in-vitro study. Arch Dent Med Res. 2015;1(3):1-8.

20. Zeidi I, Hajiagha A, Zeidi B. Reliability and validity of Persian version of the health-promoting lifestyle profile. J Mazandaran Univ Med Sci. 2012;22(supple 1):103-113.

21. Kim HJ, Choi-Kwon S, Kim H, Park YH, Koh CK. Healthpromoting lifestyle behaviors and psychological status among Arabs and Koreans in the United Arab Emirates. Res Nurs Health. 2015;38(2):133-141. doi:10.1002/nur.21644.

22. Fincham SM, Roomaney $R$, Kagee $A$. The relationship between worldview, self-efficacy, psychological distress, and a healthpromoting lifestyle among a South African undergraduate university sample. S Afr J Psychol. 2015. doi:10.1177/0081246315585935.

23. Shaheen AM, Nassar OS, Amre HM, Hamdan-Mansour AM. Factors affecting health-promoting behaviors of university students in Jordan. Health. 2015;7(1):1. doi:10.4236/health.2015.71001.

24. Mohammadian H, Mousavi SGA. Lifestyle of university students in
Kashan, Iran and factors affecting it. J Sch Public Health Inst Public Health Res. 2015;12(4):53-63.

25. Geok SK, Yusof A, Lam SK, Japar S, Leong OS, Fauzee MSO. Physical activity and health-promoting lifestyle of student nurses in Malaysia. J Biosci Med. 2015;3(3):78. doi:10.4236/ jbm.2015.33012.

26. Hwang WJ, Hong OS, Rankin SH. Predictors of health-promoting behavior associated with cardiovascular diseases among Korean blue-collar workers. Asia Pac J Public Health. 2015;27(2):NP691NP702. doi:10.1177/1010539513500338.

27. Shafieyan Z, Qorbani M, Mehr BR, et al. Association between lifestyle and hypertension in patients referred to health care centers of Ilam city in 2014. Glob J Health Sci. 2015;8(6):161. doi:10.1177/1010539513500338.

28. Mahdipour N, Shahnazi H, Hassanzadeh A, Sharifirad G. The effect of educational intervention on health promoting lifestyle: Focusing on middle-aged women. J Educ Health Promot. 2015;4:51. doi:10.4103/2277-9531.162334.

29. Safabakhsh L, Arbabisarjou A, Jahantigh M, Nazemzadeh M, Rigi SN, Nosratzehi S. The Effect of Health Promoting Programs on Patient's Life Style After Coronary Artery Bypass Graft-Hospitalized in Shiraz Hospitals. Glob J Health Sci. 2016;8(5):154.

30. Chen J, Cheng J, Liu Y, et al. Associations between breakfast eating habits and health-promoting lifestyle, suboptimal health status in Southern China: a population based, cross sectional study. J Transl Med. 2014;12:348. doi:10.1186/s12967-014-0348-1.

31. Inal S, Canbulat N, Bozkurt G. The effects of healthy lifestyle behaviors of mothers on obesity in preschool children. J Pak Med Assoc. 2015;65(10):1079-1084. 